\title{
The development and function of mucosal lymphoid tissues: a balancing act with micro-organisms
}

\author{
TD Randall ${ }^{1}$ and RE Mebius ${ }^{2}$
}

Mucosal surfaces are constantly exposed to environmental antigens, colonized by commensal organisms and used by pathogens as points of entry. As a result, the immune system has devoted the bulk of its resources to mucosal sites to maintain symbiosis with commensal organisms, prevent pathogen entry, and avoid unnecessary inflammatory responses to innocuous antigens. These functions are facilitated by a variety of mucosal lymphoid organs that develop during embryogenesis in the absence of microbial stimulation as well as ectopic lymphoid tissues that develop in adults following microbial exposure or inflammation. Each of these lymphoid organs samples antigens from different mucosal sites and contributes to immune homeostasis, commensal containment, and immunity to pathogens. Here we discuss the mechanisms, mostly based on mouse studies, that control the development of mucosal lymphoid organs and how the various lymphoid tissues cooperate to maintain the integrity of the mucosal barrier.

\section{INTRODUCTION}

Our bodies exist in symbiosis with a multitude of commensal microorganisms, collectively known as the microbiota, which colonize all epithelial and mucosal surfaces, but are particularly abundant in the gastrointestinal tract. In fact, humans are comprised of an estimated $10^{13}$ human cells ${ }^{1}$ and $10^{14}$ microbial cells of thousands of species, ${ }^{2}$ which makes the definition of 'self somewhat complicated. Commensal microbiota are essential for the digestion of food and generate essential nutrients and vitamins that are made available to the host. ${ }^{3}$ The microbiota also have profound effects on the immunological development of the host by stimulating the host immune system to respond more quickly and effectively to pathogen challenge and, via bacterial antagonism, inhibiting the colonization of mucosal surfaces by pathogenic microorganisms. ${ }^{4}$ Despite the beneficial properties of commensal microorganisms at mucosal surfaces, if they are not properly contained, they can cause local or systemic infections that can lead to chronic or acute inflammation and even death. ${ }^{5}$ Thus, although commensal colonization is clearly beneficial to the human host, the immune system must use noninflammatory mechanisms efficiently to prevent commensal encroachment into systemic sites, while simultaneously allowing their maintenance at mucosal surfaces.

In addition to providing an interface between commensal microbiota and the host, mucosal surfaces are often sites of pathogen entry. Viral, fungal, parasitic, and bacterial pathogens often colonize mucosal surfaces, use mucosal routes to gain entry to systemic sites, and shed their progeny into mucosal secretions to infect new hosts. Unlike commensals, pathogens are clearly detrimental to the host and the immune system must be capable of detecting them and mounting an immune response that is vigorous enough to clear the infection without unduly compromising the mucosal barrier. To make matters more complicated, the immune response must simultaneously discern the difference between commensals, pathogens, and inert antigens like those from food or airborne particles and respond appropriately, ${ }^{6,7}$ as inappropriate responses to nonpathogens may lead to chronic inflammatory conditions, such as inflammatory bowel disease, asthma, or allergies.

Immune responses are facilitated by organized lymphoid tissues, ${ }^{8}$ which have evolved mechanisms to collect antigens from peripheral and mucosal tissues and efficiently present them to lymphocytes in ways that lead to rapid and robust

${ }^{1}$ Department of Medicine, Division of Clinical Immunology and Rheumatology, University of Alabama at Birmingham, Birmingham Alabama, USA and ${ }^{2}$ Department of Molecular Cell Biology and Immunology, VU University Medical Center, Amsterdam, The Netherlands. Correspondence: RE Mebius (r.mebius@vumc.nl)

Received 6 December 2013; accepted 24 January 2014; published online 26 February 2014. doi:10.1038/mi.2014.11 
immune responses to pathogens, as well as noninflammatory or tolerogenic immune responses to commensal organisms and inert antigens. The structure of lymphoid organs maximizes encounters between naive lymphocytes, antigens, and antigenpresenting cells, and provides a microenvironment that sustains the proliferation, differentiation, and survival of activated cells. ${ }^{9}$ Secondary lymphoid organs are strategically located within the drainage areas of most tissues in the body, including mucosal surfaces such as the respiratory tract, the gastrointestinal tract, and the reproductive tract. Importantly, each lymphoid organ supports immune responses that are appropriate for the tissue that they drain and for the type of antigen that they encounter. Here we will describe the different types of mucosa-associated lymphoid tissues, the pathways by which they differentiate, and how they control mucosal immunity and homeostasis.

\section{STRUCTURE OF MUCOSAL LYMPHOID TISSUES}

There are four predominant types of lymphoid organs that serve mucosal sites: encapsulated draining lymph nodes (LNs), mucosal lymphoid tissues, which are directly associated with mucosal tissues, fat-associated lymphoid tissues, and nonprogrammed, ectopically induced, tertiary lymphoid tissues. Each of these tissues has distinct developmental origins and structural characteristics (Figure 1) and each of these tissues performs specialized functions in the regulation of mucosal immunity. The encapsulated LNs, such as the mesenteric LNs that drain the intestines and the cervical and mediastinal LNs that drain the upper and lower respiratory tract, share similar structures. These bean-shaped organs collect antigen and antigen-presenting cells via afferent lymphatics that deliver their contents to the subcapsular sinus on the cortical side of the LN, where they are filtered through a layer of sinus-lining macrophages and dendritic cells (DCs) and percolate through the T-cell zone. B-cell follicles are found around the edge of the cortical region, whereas the T-cell zone is centrally located in the cortex. Lymphocytes enter the LNs through high endothelial venules (HEVs) that are found in the $\mathrm{T}$ zone and that are surrounding the B-cell follicles, and then exit the LN through the medullary cords, and subsequently through the efferent lymphatic vessels (Figure 1).

In contrast, mucosal lymphoid tissues, such as the Peyer's patches in the small intestine, colonic patches in the colon, ${ }^{10}$ isolated lymphoid follicles (ILFs) ${ }^{11}$ and cryptopatches in both the small intestine and the colon, ${ }^{12}$ the nasal-associated lymphoid tissue (NALT) in the nasal passages, ${ }^{13}$ the tonsils and adenoids in the nasopharynx, and the tear duct-associated lymphoid tissue (TALT) ${ }^{14}$ in the eye, are not encapsulated and are embedded directly in the submucosa of the organs in which they are found. These tissues lack afferent lymphatics and instead collect antigens directly from the mucosal surface across a specialized epithelial layer known as the dome epithelium or the follicle-associated epithelium. This epithelial layer contains specialized epithelial cells termed $M$ cells for the distinct microfold ridges on their apical surface. ${ }^{15} \mathrm{~A}$ distinct layer of DCs is found immediately below the dome epithelium ${ }^{16}$ and

\section{a Encapsulated lymphoid organs}

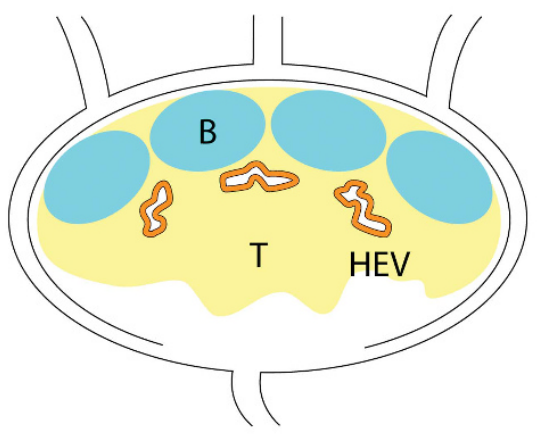

b Lymphoid organs associated with epithelium

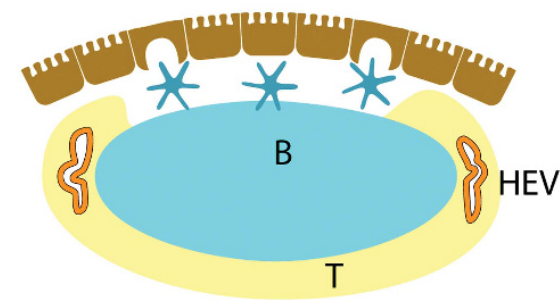

c Fat-associated lymphoid organs

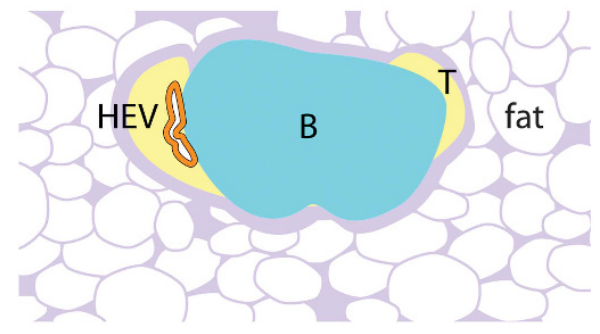

d Ectopic lymphoid organs

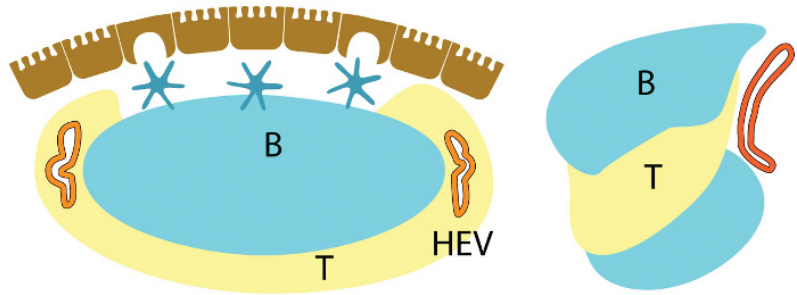

Figure 1 Different types of lymphoid organs are present at mucosal sites. (a) Encapsulated lymphoid organs, such as lymph nodes, contain incoming afferent lymphatic vessels through which antigen and antigenpresenting cells enter the lymphoid organs. Efferent lymphatic vessels carry the lymph away from the lymphoid organ. (b) In nonencapsulated lymphoid organs, which are associated with the epithelium, antigen comes in through the follicle-associated epithelium, overlaying the B-cell areas. This epithelial layer contains specialized microfold cells ( $M$ cells). Dendritic cells are located right underneath this follicle-associated epithelium, enabling them to take up and process the antigen. Efferent lymphatic vessels are in place to transport lymph away from the lymphoid tissues. (c) Fat-associated lymphoid organs, such as fat-associated lymphoid clusters and milky spots, also lack a capsule. They can obtain antigen by lymphatic drainage directly from the intestine as well as from the peritoneal cavity. (d) Ectopic lymphoid follicles can form in association with the epithelium, as well as perivascular structures, which are away from the epithelium. HEV, high endothelial venules; B, B-cell area; T, T-cell area. 
many of these cells are enfolded within the basolateral pocket of $M$ cells, where they receive antigens transported from the mucosal surface by the $\mathrm{M}$ cells. B-cell follicles fill the dome region of mucosal lymphoid organs and the $\mathrm{T}$ zone is typically found to the sides of the B-cell follicles or between follicles (Figure 1). Like encapsulated LNs, the HEVs of mucosal lymphoid organs are found surrounding the B-cell follicles and in the T-cell zone. Also like LNs, mucosal lymphoid organs such as Peyer's and colonic patches have efferent lymphatics, which are used as a point of egress for activated or recirculating cells. For ILFs, however, it has not been established whether efferent lymphatic vessels are in place to perform such a function.

The fat-associated lymphoid tissues are distinct from both LNs and classic mucosal lymphoid tissues in that they are not encapsulated and are not directly under a mucosal epithelium. Instead, the fat-associated lymphoid clusters (FALCs) ${ }^{17}$ of the mesentery and the milky spots of the omentum ${ }^{18}$ are embedded in the adipose tissue. Although the FALCs may receive antigens and cells via the lymphatic drainage from the intestines, ${ }^{17}$ they are also able to acquire antigens directly from the peritoneal cavity via fenestrations in the mesothelial layer that overlays the mesentery (Figure 1). Similarly, the milky spots of the omentum acquire antigens and cells exclusively from the peritoneal cavity and appear to be a major site through which the peritoneal fluid is collected. ${ }^{19}$ Milky spots are dominated by large central clusters of B cells, but as they seem to lack follicular DC (FDC) networks in the B-cell area, ${ }^{18}$ they do not have B-cell follicles per se. In contrast, the T-cell zone in milky spots is somewhat limited and seems to surround the B-cell areas. HEVs are found around the follicles of milky spots, although unlike HEVs of Peyer's patches and mesenteric LNs, the HEVs of milky spots express peripheral LN addressin and not mucosal addressin cell adhesion molecule. ${ }^{18}$ FALCs have even less of an organized structure than milky spots, but are similarly dominated by B1 cells, consistent with the idea that cells in the peritoneal cavity can easily translocate to these tissues.

Unlike the lymphoid tissues mentioned above, all of which develop their initial anlage independently of antigen or microbial colonization, ectopic lymphoid follicles, such as bronchusassociated lymphoid tissue (BALT) or gastric-associated lymphoid tissue, are formed after birth in response to inflammation or infection..$^{20}$ Nevertheless, the structure of ectopic lymphoid tissues mimics that of conventional lymphoid tissue in many ways. For example, BALT often has large central B-cell follicles and separated T-cell areas, specialized stromal cells as well as HEVs and lymphatics (Figure 1). In some cases, well-developed BALT areas have a dome epithelium with identifiable M cells, similar to those in the Peyer's patches or NALT. However, BALT may also be found in perivascular areas of the lung and lack a dome epithelium. Moreover, BALT can sometimes be observed with a well-developed B-cell follicle and even germinal centers, but lack a defined T-cell area. In fact, a wide range of ectopic lymphoid structures can be observed, from loose clusters of B cells to large multifollicular structures. However, unlike ILFs, which develop from cryptopatches at defined sites, ectopic lymphoid tissues seem to develop in a wide variety of locations from precursor structures that are not yet defined.

\section{MUCOSAL LYMPHOID ORGAN DEVELOPMENT}

Lymphoid organ development requires reciprocal interactions between a variety of lymphoid tissue initiator or inducer (LTi) cells and lymphoid tissue organizer or stromal cells. ${ }^{21}$ LTi cells are innate lymphoid cells (ILCs) that require the transcription factors, RAR-related orphan receptor $\gamma \mathrm{t}(\mathrm{ROR} \gamma \mathrm{t})$, and Id2, and express CXC-chemokine receptor 5 (CXCR5) and CCR7, the receptors for CXC-chemokine ligand 13 (CXCL13) and CCL19/CCL21, respectively. ${ }^{22-25}$ Importantly, LTi cells express lymphotoxin, ${ }^{26}$ which triggers the nuclear factor- $\kappa \mathrm{B}$ signaling pathway in lymphotoxin $\beta$ receptor-expressing lymphoid tissue organizer cells, and leads to the enhanced expression of homeostatic chemokines and cytokines, including CXCL13, CCL19, CCL21, interleukin-7 (IL-7), and RANK (receptor activator of NF- $\mathrm{kB}$ ) ligand, which in turn attract and support the survival of LTi cells. ${ }^{27,28}$ Ultimately, the lymphoid tissue organizer cells differentiate into the various stromal cell types, such as fibroblastic reticular cells ${ }^{29}$ and FDCs, ${ }^{30}$ that form the scaffolding of the lymphoid tissue and help to compartmentalize lymphocytes and DCs into their appropriate anatomic locations. Once lymphoid tissues are formed, lymphotoxin continues to be expressed by adaptive lymphocytes, particularly $\mathrm{B}$ cells, ${ }^{31}$ which are important for maintaining the lymphotoxin:chemokine feedback loop, and as a result, the structure of the lymphoid organ.

Although individual mucosal lymphoid tissues develop following the same general program, each has unique characteristics. For example, the development of secondary lymphoid organs is temporally regulated-mesenteric LNs in mice begin to develop on embryonic day E9-10, brachial LNs on E13, axillary LNs on E15, inguinal LNs on E16, and popliteal LNs on E17. ${ }^{32}$ In contrast, Peyer's patches are still developing up until birth ${ }^{32}$ and the TALT and NALT develop after birth. ${ }^{14,33}$ The cryptopatches, ILFs, and milky spots of the omentum also develop after birth and are partially dependent on the presence of microbiota to attain their full maturation. ${ }^{34,35}$ In addition to the developmentally programmed lymphoid organs, ectopic lymphoid tissues like BALT only develop following infection or inflammation. ${ }^{36-38}$

As described above, the lymphotoxin-driven expression of homeostatic chemokines like CXCL13 is important for the development of essentially all lymphoid tissues. ${ }^{39}$ However, submucosal lymphoid tissues like Peyer's patches, ILFs, and NALT express additional homeostatic chemokines, such as CCL20 and CCL $9,{ }^{40}$ that attract populations of DCs and B cells to the subepithelial dome region. Like other homeostatic chemokines, CCL20 expression in the dome epithelium requires lymphotoxin signaling. ${ }^{41}$ The importance of these chemokines is illustrated in mice lacking CCR6, the receptor for CCL20, which is required on B cells for the proper maturation of ILFs from cryptopatches in the small intestine. ${ }^{42,43}$ CCR6 is also expressed on putative LTi cells in cryptopatches, ${ }^{44}$ although CCR6 expression on LTi cells is not critical for 
cryptopatch formation. ${ }^{34,35,44}$ Interestingly, the requirement for the various chemokines in ILF formation is distinct between the small intestine and the colon; in other words, ILFs do not form in the absence of CCL20 or CXCL13 in the small intestine, but they are present in the colon of mice in which the CCL20 or CXCL13 signaling axis is disrupted, although with a disturbed architecture in CXCL13-deficient mice. ${ }^{34,35}$ There is also a difference between tissues in the gut and the respiratory tract, as NALT development is not markedly disrupted in CCR6deficient mice (TDR unpublished).

\section{ROLE OF LTI CELLS}

Although the development of peripheral LNs is entirely dependent on the activities of LTi cells and lymphotoxin, many of the mucosal lymphoid tissues develop in the apparent absence of this pathway (Table 1). For example, NALT and TALT both develop independently of lymphotoxin, albeit with disrupted architecture. ${ }^{14,33,45}$ Furthermore, both TALT and NALT develop in ROR $\gamma t$-deficient mice, which lack the archetypical LTi cells, suggesting that the development of these tissues does not involve LTi cells. ${ }^{14,33,45}$ However, the development of NALT, but not TALT, does depend on Id2. ${ }^{14,33}$ Given that Id2 is required for the differentiation of all ILCs, another ILC family member could be responsible for the inductive signals required for NALT formation ${ }^{46}$ (Table 1). Interestingly, although all ILCs require Id2, only the LTi-containing ILC3 subset requires ROR $\gamma$ t, which promotes the expression of cytokines like IL-17 and IL-22. ${ }^{46}$ In contrast, other ILC family members, such as ILC1 or ILC2 cells, express interferon $-\gamma$ or
IL-5/IL-13, respectively. ${ }^{46}$ Although the involvement of these cytokines in lymphoid tissue formation has not been documented, the development of FALCs depends on natural helper cells (ILC2 cells), which produce IL-5 and IL-13. ${ }^{17}$

Another fat-associated lymphoid tissue, the milky spots of the omentum, also develops in the absence of lymphotoxin, ${ }^{18}$ although they do so with some structural defects. Their formation, however, does not require LTi cells, as milky spots are formed in both $R O R \gamma t$-deficient as well as $I d 2$-deficient mice, ${ }^{18}$ suggesting that ILCs may not be involved at all (Table 1). Given that milky spots develop after birth at a time when adaptive lymphocytes are plentiful, it is likely that B cells, particularly B1 cells, promote their differentiation. ${ }^{47}$ Intriguingly, although they do posses a stromal cell network, milky spots do not have identifiable $\mathrm{FDCs},{ }^{18}$ suggesting that the functions of both LTi cells and lymphoid tissue organizer cells may be performed by different cell types during milky spot differentiation and may account for their unique developmental and functional characteristics.

Ectopic follicles in both the lung and the gut also appear to develop independently of LTi cells, although not necessarily independent of lymphotoxin. ${ }^{36,48}$ For example, although ROR $\gamma t$-deficient mice lack LNs, Peyer's patches, ILFs, and even cryptopatches owing to the loss of LTi cells, these mice develop ectopic follicles in the submucosa of the intestine. ${ }^{48}$ Interestingly, B cells seem functionally to replace LTi cells in this context and serve as an essential source of lymphotoxin that promotes the development of the microbiota-driven formation of ectopic follicles. ${ }^{48}$ Similarly, the ectopic development of

Table 1 Requirements for the formation of mucosal lymphoid tissues

\begin{tabular}{|c|c|c|c|c|c|c|c|}
\hline \multicolumn{8}{|c|}{ Formation dependent on } \\
\hline Peyer's patches & + & + & + & + & - & & SI \\
\hline Cryptopatches SI & + & + & + & ND & - & & SI \\
\hline Cryptopatches colon & + & - & + & ND & - & & Colon \\
\hline TALT & - & - & - & - & - & $\begin{array}{l}\text { Architecture disturbed in } \mathrm{LT}^{-/-} \text {, } \\
\text { Cxcl13 }{ }^{-\prime-} \text { mice }\end{array}$ & Tear duct \\
\hline ILFs in the SI & + & + & + & ND & + & & SI \\
\hline ILFs in the colon & + & - & + & ND & - & $\begin{array}{l}\text { Architecture disturbed in } \\
\text { Cxcl13 }{ }^{-1-} \text { mice }\end{array}$ & Colon \\
\hline FALCs & - & ND & - & + & $\begin{array}{l}-/+ \text { Number } \\
\text { and size affected }\end{array}$ & Formation dependent on ILC2 & Fat \\
\hline BALT & - & - & - & - & $\begin{array}{l}\text { Promote BALT } \\
\text { development }\end{array}$ & $\begin{array}{l}\text { Architecture disturbed } \\
\text { in } \mathrm{LT} \alpha^{-/-} \mathrm{Cxcl1} 3^{-/-}\end{array}$ & Lung \\
\hline
\end{tabular}

Abbreviations: BALT, bronchus-associated lymphoid tissue; CXCL13, CXC-chemokine ligand 13; FALC, fat-associated lymphoid cluster; ILC2, type 2 innate lymphoid cells; ILF, isolated lymphoid follicle; LT $\alpha \beta$, lymphotoxin $\alpha \beta$; LT $\beta R$, lymphotoxin $\beta$ receptor; NALT, nasal-associated lymphoid tissue; ND, not determined; ROR $\gamma$ t, RAR-related orphan receptor $\gamma \mathrm{t}$; SI, small intestine; TALT, tear duct-associated lymphoid tissue.

+ , Required; - , not required. 
BALT occurs independently of both ROR $\gamma \mathrm{t}$ and Id $2,{ }^{36}$ implying that LTi cells are not involved (Table 1). Nevertheless, lymphotoxin is important for the organization of BALT, although perhaps not its development. Mice lacking lymphotoxin or the lymphotoxin $\beta$ receptor often develop extensive lymphoid aggregates in the lungs in the same locations one would normally observe BALT. ${ }^{49}$ However, these lymphoid aggregates fail to segregate $\mathrm{B}$ and $\mathrm{T}$ cells, do not form identifiable FDCs and fail to develop HEVs, ${ }^{49}$ suggesting that many of the architectural features of BALT are dependent on lymphotoxin, even though the initial expression of CXCL13 and the recruitment of lymphocytes can occur in its absence. Moreover, even though CXCL13 is required for the development of most lymphoid organs, ${ }^{39}$ mice lacking CXCL13 still form BALT with segregated B- and T-cell areas, ${ }^{50}$ although the B-cell areas lack FDCs (Table 1). Nevertheless, CXCL13 is important for the development of BALT, as the combined loss of CXCL13, CCL19, and CCL21 completely abrogates BALT development, whereas the loss of either CXCL13 or CCL19/CCL21 only leads to minor structural defects. ${ }^{50}$

\section{ROLE OF MICROBIOTA, INFECTION, AND INFLAMMATION IN MUCOSAL LYMPHOID ORGAN DEVELOPMENT}

Most lymphoid organs develop during embryogenesis in a sterile environment. However, some mucosal lymphoid organs complete or even initiate their development after birth and are markedly influenced by exposure to commensal microbiota. ${ }^{51}$ For example, Peyer's patches, NALT, TALT, and cryptopatches all develop in germ-free mice. ${ }^{14,21,34}$ However, the cryptopatches mature in response to microbial colonization of the gut and accumulate B cells and ultimately transform into ILFs. ${ }^{12,35}$ The requirements for the transition from cryptopatches to ILFs are different between the small and the large intestine: counterintuitively the maturation of ILFs in the small intestine depends on the microbiota, whereas the maturation of ILFs in the colon, where the microbial density should be the highest, occurs in a microbiota-independent, yet Myd88-dependent manner $^{34,35}$ (Table 1). Similarly, environmental exposure helps the maturation of NALT. ${ }^{52}$ In part, exposure to antigen causes some level of inflammation that leads to immune reactivity and expands germinal centers, just as it would in conventional lymphoid organs. However, microbial triggers also promote $\mathrm{M}$-cell differentiation and maturation in both the gut ${ }^{53,54}$ and the airways. ${ }^{55,56}$ Given the interactions between $\mathrm{M}$ and $\mathrm{B}$ cells, it is not surprising that microbial exposure leads to the accumulation of B cells, the differentiation of a dome epithelium, and ultimately to the maturation of mucosal lymphoid tissues.

The microbiota also has an important role in the maturation of FALCs in the mesentery and milky spots in the omentum. The number and size of FALCs and milky spots are reduced in germ-free mice and their cellular composition is altered, ${ }^{57}$ suggesting that despite their placement in the peritoneal cavity, which under steady-state conditions should not be colonized with microbes, these sites are exposed to gut-associated commensals or their products. Moreover, upon oral administration of indomethacin or dextran sulfate sodium, both of which perturb the intestinal epithelium and lead to inflammation and leakage of intestinal contents, the number and size of milky spots is markedly increased. ${ }^{58}$ Acute peritoneal inflammation with sterile stimuli-like LPS also causes an immediate activation of peritoneal macrophages and B1 cells, which rapidly home to the milky spots. ${ }^{58}$ Even sterile peritoneal dialysis leads to increases in the number and size of the milky spots. ${ }^{19}$ Similarly, the FALCs are stimulated upon infection with $N$. brasiliensis, which leads to ILC2 activation, IL-5 and IL-13 expression, and parasite expulsion. ${ }^{17}$ Thus, the fatassociated lymphoid tissues in the peritoneal cavity are highly sensitive to both steady-state and inflammatory conditions in the intestinal lumen.

Persistent or repeated damage to the mucosal epithelium can allow microbes and their products to contact the underlying tissue, resulting in chronic inflammation or infection and leading to the development of ectopic or tertiary lymphoid tissues. For example, BALT can form in response to chronic inflammation, such as cigarette smoke, ${ }^{59,60}$ exposure to allergens ${ }^{61}$ or autoantigens, ${ }^{62,63}$ idiopathic pulmonary arterial hypertension, ${ }^{64}$ or following infection. ${ }^{37,38,65-67} \mathrm{~A}$ common feature of ectopic lymphoid tissue development is the expression of CXCL13, which is often not expressed in peripheral nonlymphoid organs, but is markedly increased at sites of tertiary lymphoid tissue development. ${ }^{65}$ Although CXCL13 expression in conventional lymphoid organs is controlled by retinoic acid signaling ${ }^{25}$ and homeostatic signaling through the lymphotoxin $\beta$ receptor, the expression of CXCL13 in the lungs can also be acutely triggered by IL-17, ${ }^{36,64,68}$ independently of lymphotoxin or retinoic acid. Although LTi cells express IL-17, the important source of IL-17 in BALT formation is initially $\gamma \delta \mathrm{T}$ cells followed by $\alpha \beta \mathrm{T}$ cells with a $\mathrm{T}$ follicular helper phenotype. ${ }^{36,69}$ However, once enough activated $\mathrm{B}$ and $\mathrm{T}$ cells accumulate at the appropriate sites in the lung, they maintain CXCL13 expression independently of IL-17 via their homeostatic production of lymphotoxin, which is essential to maintain BALT structure. ${ }^{36,37}$ BALT development has a similar requirement for CXCR5-expressing, IL-17-producing $\mathrm{T}$ cells following vaccination and challenge with Mycobacterium tuberculosis. ${ }^{69,70}$ Ectopic lymphoid tissues in other locations, such as those in the gastric mucosa of the stomach upon Helicobacter pylori infection ${ }^{71,72}$ and those in the small intestine following mucosal irritation or failure to contain commensal microbiota, ${ }^{48,73}$ have similar requirements for CXCL13 and lymphotoxin. ${ }^{71,72,74}$ However, the initial inflammatory trigger that leads to the development of these ectopic tissues is not known. Given that IL-17- and IL-22-producing helper T cells are essential for protective immunity against Helicobacter, ${ }^{75}$ these cytokines may be involved.

Although IL-17 is clearly involved in the formation of ectopic follicles under some circumstances, ${ }^{36,64,68}$ it is not essential in all cases, as BALT and ectopic follicles in the gut both develop in $R O R \gamma t$-deficient mice, ${ }^{36,48}$ which have essentially no capacity to produce IL-17. Moreover, BALT formation can be induced in adults in the absence of IL-17a and IL-17f by pulmonary infection with modified vaccinia Ankara virus. ${ }^{76}$ However, it is 
currently unclear which pathways are involved. Nevertheless, the role of DCs, which are required for the maintenance of BALT, ${ }^{37}$ should not be overlooked, as these cells are not associated with the development of conventional lymphoid organs, but are important for BALT formation. Finally, signaling via other innate inflammatory cytokines, such as IL-1, are also likely to be involved in the formation of ectopic follicles, as these cytokines are important in diseases like chronic obstructive pulmonary disease (COPD), ${ }^{77,78}$ which feature the development of ectopic follicles. Thus, both microbial and inflammatory stimuli promote BALT formation via a variety of pathways that are not used in the development of conventional lymphoid organs.

\section{ANTIGEN ACQUISITION IN MUCOSAL LYMPHOID TISSUES}

The acquisition of antigen is essential for the function of any lymphoid organ. Conventional LNs acquire antigen through afferent lymphatics, which drain local nonlymphoid tissues and collect antigens and antigen-presenting cells that are activated by invading pathogens or even commensal organisms that have penetrated the mucosal barrier and elicited a local inflammatory response. In fact, the lamina propria of the mucosal epithelium is replete with tissue DCs that, when activated by microbial stimuli, rapidly migrate to the mesenteric LNs (from the gut), the mediastinal LNs (from the lower respiratory tract), or the cervical LNs (from the upper respiratory tract). ${ }^{7,79}$ The migratory DCs include both the CD $103^{+}$DCs and the CD11b ${ }^{\text {hi }}$ DCs, which reside in different locations and perform different functions, ${ }^{80-83}$ depending on the type of antigen, the route of exposure, and the extent of inflammation. 84

LNs that drain mucosal sites also have access to lumenal antigens under steady-state conditions, which requires mechanisms for transporting antigens across the mucosal epithelium. One such mechanism involves goblet cell-associated antigen passages or GAPs, which acquire soluble luminal antigens and transports them to underlying DCs, particularly $\mathrm{CD}_{103}{ }^{+}$DCs. ${ }^{85}$ Given that $\mathrm{CD} 103^{+}$DCs are associated with the induction of immunological tolerance under steady-state conditions, ${ }^{86,87}$ GAPs may be important for the maintenance of tolerance to food antigens. Consistent with this idea, the function of GAPs is linked to the secretory capacity of goblet cells ${ }^{85}$ and defects in goblet cells are linked to intestinal inflammation. ${ }^{88,89}$ GAPS are observed in the small intestine, but not in the stomach, cecum, or colon, and have not yet been examined in the respiratory tract. ${ }^{85}$

In addition to the active sampling of luminal contents by specialized epithelial cells, some DCs can directly sample antigens by extending dendrites between epithelial cells. For example, CX3CR1-expressing DCs in the intestinal villi project dendrites between epithelial cells into the intestinal lumen and thereby capture antigens. ${ }^{90} \mathrm{CX} 3 \mathrm{CR} 1$ is necessary for these DCs to extend dendrites into the lumen and for bacterial uptake. ${ }^{91}$ These CX3CR1-expressing DCs are often perceived as nonmigratory ${ }^{92}$ and are suggested to represent immune effectors rather than immune inducers. ${ }^{93}$ However, recent data suggest that commensal microbiota actually restrain the migratory ability of CX3CR1 ${ }^{+}$DCs, but upon inflammation, these cells express CCR7, traffic antigens and bacteria to the LN and trigger T- and B-cell responses. ${ }^{94}$

$\mathrm{M}$ cells are another mechanism for antigen transport across the mucosal epithelium. Although M cells are most often associated with a dome epithelium overlaying mucosal lymphoid tissues, ${ }^{15,95,96}$ they are also found in the normal villi of the small intestine ${ }^{97}$ and the respiratory epithelium. ${ }^{98}$ Unlike GAPs, which are limited to sampling low-molecular-weight antigens, $M$ cells efficiently transcytose particulate antigens and even whole bacteria ${ }^{98}$ - a process that is facilitated by a variety of receptors, including glycoprotein $2,{ }^{54}$ uromodulin, ${ }^{99}$ and annexin $\mathrm{V},{ }^{100}$ all of which bind to bacterial components. In many cases, the organisms transported by $M$ cells are commensal organisms that are part of the normal microbiota. However, some pathogens, including mouse mammary tumor virus ${ }^{101}$ group A streptococcus, ${ }^{102}$ and Burkholderiapseudomallei ${ }^{103}$ have taken advantage of $\mathrm{M}$ cells to hitch a ride across the epithelium. M cells have a basolateral pocket, which is often filled with a variety of hematopoietic cells, including CCR6expressing $\mathrm{B}$ cells and DCs, ${ }^{43}$ which are poised to receive transported antigens. CX3CR1-expressing DCs are also found in the basolateral pocket of $\mathrm{M}$ cells and can extend dendrites through pores in $\mathrm{M}$ cells to sample directly antigens overlaying the dome epithelium of Peyer's patches. ${ }^{104}$

Unlike antigen acquisition in LNs and mucosal lymphoid tissues, antigen acquisition in ectopic lymphoid tissues is poorly understood. Tissues like BALT are initially described as classic mucosal lymphoid organs with a dome epithelium and $M$ cells. ${ }^{105-108}$ However, BALT does not always have a dome epithelium and some areas of BALT are perivascular or are found in the lower airspaces that lack an association with either airways or arterioles. ${ }^{109}$ Moreover, ectopic lymphoid tissues in the intestine and gastric mucosa also lack a dome epithelium and are embedded in the tissue itself. Thus, these tissues must acquire antigens via alternative mechanisms.

One possible way in which ectopic lymphoid tissues collect antigens is via afferent lymphatics. Lymphatic vessels are observed surrounding ectopic follicles. ${ }^{20,63}$ However, it is not clear whether these are afferent lymphatics that bring antigens and cells from distal regions or whether they are efferent lymphatics that return lymphocytes to the circulation. Histological evidence of DCs and macrophages, filled with diesel exhaust particles, ${ }^{110}$ silica particles, ${ }^{111}$ cigarette smoke particles, ${ }^{112}$ and other antigens within BALT, ${ }^{38}$ suggests that these cells may have acquired antigens and then migrate into BALT. Consistent with this possibility, live imaging of BALT shows that DCs can migrate from the lung airways into BALT, ${ }^{38}$ demonstrating that DCs can enter BALT via afferent lymphatics or directly across the epithelium. ${ }^{38}$ However, in many cases, ectopic lymphoid tissues seem to form directly surrounding pathogens like Helicobacter pylori or Mycobacterium tuberculosis, ${ }^{63,66-68}$ in which case the antigen is already present inside the follicle. Thus, there may be multiple ways for ectopic lymphoid tissues to acquire antigen. 
If pathogens, commensals, or even microbial products escape from the gastrointestinal tract into the peritoneal cavity owing to intestinal trauma or inflammation, they will be collected by the milky spots of the omentum or the FALCs. ${ }^{17,19}$ These lymphoid clusters are open to the peritoneal cavity via fenestrations in the overlaying mesothelium. ${ }^{113}$ Peritoneal fluid is continually flowing from the peritoneal cavity through the milky spots and FALCs, ${ }^{19}$ which capture cell-free antigens and particles, as well as a wide variety of cell types that may be in the peritoneal cavity. For example, upon activation, peritoneal macrophages rapidly migrate to the milky spots and carry with them any organisms or antigens they have engulfed. ${ }^{58}$ Although peritoneal macrophages are unlikely to be a primary antigenpresenting cell, the milky spots also have a variety of DCs that are capable of priming and cross-priming $\mathrm{T}$ cells. B1 cells are also abundant in the peritoneal cavity and, upon activation by microbial signals, these cells also rapidly migrate to the milky spots. ${ }^{47,58}$ Given the dependence of milky spot development on microbial colonization in the gut, ${ }^{57}$ it seems that they are probably continuously exposed to microbial products even under steady-state conditions.

\section{MUCOSAL IGA RESPONSES}

Considering the numerous ways in which mucosal antigens can be sampled, it is difficult to ascribe a particular function or activity to any individual type of mucosal lymphoid organ. However, the generation of $\mathrm{B}$ cells that have isotype-switched to immunoglobulin A (IgA) is a hallmark feature of mucosal tissues, of which Peyer's patches serve as the prototypical model. ${ }^{114}$ IgA-expressing B cells dominate germinal centers in Peyer's patches and the enzyme, activation-induced cytidine deaminase, which is required for isotype switching, ${ }^{115}$ is expressed in those cells as well. ${ }^{116,117}$ Moreover, IgA switch circles, which are a by-product of isotype switching to $\operatorname{IgA}{ }^{118}$ and postswitch IgA circle transcripts, ${ }^{119}$ are also abundant in Peyer's patch B cells.

Despite their undisputed ability to promote the differentiation of IgA-expressing B cells, Peyer's patches are not absolutely necessary for the production of IgA in the gastrointestinal tract, as ILFs can make considerable amounts of IgA in mice that lack Peyer's patches and LNs. ${ }^{120-122}$ One important difference is that the generation of IgA-producing B cells is dependent on $\mathrm{T}$ cells in the Peyer's patches, while this is a T-cell-independent process in ILFs. ${ }^{120}$ Switching to IgA may also occur in the lamina propria itself outside the organized lymphoid tissues. ${ }^{118}$ However, this observation is controversial, ${ }^{116,117}$ owing to the difficulty of isolating lamina propria in the absence of any contaminating ILFs.

The milky spots are also proposed to contribute to intestinal IgA production. Both the peritoneal cavity and the omentum are filled with B1 cells, which efficiently switch to IgA in vitro when stimulated with microbial products and cytokines like tumor growth factor- $\beta .^{58}$ Although B1 cells are unlikely to contribute to IgA elicited by $\mathrm{T}$-dependent antigens, they may well contribute to "natural" IgA. Consistent with this idea, B1 cells also preferentially home to the peritoneal cavity and the small intestine, ${ }^{58,123}$ implying that they may contribute to mucosal IgA responses. However, other studies demonstrate that B1 cells in the peritoneal cavity are primarily responsible for the production of natural IgM, but contribute only minimally to intestinal IgA under steady-state conditions. ${ }^{124}$

By analogy to canonical mucosal lymphoid organs like Peyer's patch, one might expect that NALT would also promote the differentiation of IgA-producing B cells. While nasal immunization using cholera toxin as an adjuvant typically elicits IgA-secreting B cells in the NALT, ${ }^{125-129}$ nasal immunization with protein-containing microparticles primarily elicits IgG responses, ${ }^{130}$ which appear in the NALT before their appearance in cervical LNs. In contrast, nasal infections with viruses $^{131-133}$ result in mixed B-cell responses consisting of both IgG- and IgA-secreting cells in the NALT. Nevertheless, nasal influenza infection leads to higher frequencies of IgA B cells in NALT than in mediastinal LNs, lung, or spleen. ${ }^{134-136}$ Moreover, NALT selectively promotes the development of high-affinity IgA memory B cells over IgG memory cells. ${ }^{137}$ Thus, although NALT is not exclusively biased toward IgA production, IgA is favored over IgG in the memory compartment. However, NALT is not absolutely necessary for adequate immune responses, as in its absence, nasal immune responses to influenza and protection against pneumococcal antigens can still occur. ${ }^{138,139}$ In contrast, cervical LNs are important to achieve nasal immune responses of a normal magnitude. ${ }^{139}$

\section{IMMUNITY IN ECTOPIC LYMPHOID TISSUES}

Ectopic lymphoid tissues, like those in the lung (BALT) or those in the stomach or the gut also have a role in local immune responses. Given that these tissues are responding to mucosal antigens, one might expect that isotype switching in these sites would primarily result in IgA-producing B cells. However, IgGsecreting cells often predominate over IgA-secreting cells in BALT. ${ }^{106,140}$ Nevertheless, IgA is produced in BALT under a variety of conditions, ${ }^{141}$ including after influenza infection. ${ }^{37}$ Moreover, BALT seems to generate IgA-secreting plasma cells that home to the lung as well as IgG-secreting plasma cells that home to the bone marrow. ${ }^{37}$ Importantly, BALT generate the long-lived isotype-switched plasma cells and maintain virusneutralizing antibodies in the serum and bronchial lavage fluid that can completely prevent infection following a secondary challenge. ${ }^{142}$ Isotype switching in BALT is not restricted to IgG and IgA, as IgE is often found in BALT areas of patients with allergies $^{143}$ or in experimental animals that have been sensitized to antigens under type 2 helper $\mathrm{T}$ cell-inducing conditions. ${ }^{144,145}$ Ectopic follicles at other mucosal sites, including those in the small intestine responding to microbiota and those in the gastric mucosal responding to Helicobacter pylori, also preferentially promote IgG-producing rather than IgA-producing B cells, suggesting that immune responses in these tissues have more characteristics of systemic responses than mucosal responses. ${ }^{48,71}$ Consistent with this idea, peripheral LN addressin is commonly expressed by HEVs in ectopic follicles, such as BALT, whereas mucosal addressin cell adhesion molecule is rarely observed. 
As noted above, it is difficult to assign a particular immune function to specific lymphoid tissues. However, mice lacking spleen, LNs, and Peyer's patches generate normal pulmonary B- and T-cell responses to influenza, ${ }^{65,142,146}$ suggesting that BALT is sufficient to initiate and expand some types of pulmonary immune responses. Similar studies using splenectomized lymphotoxin-deficient mice, which also lack LNs and Peyer's patches, show that immune responses to pulmonary infection with Mycobacterium tuberculosis ${ }^{147,148}$ and Leishmania major antigens ${ }^{149}$ are intact in the absence of conventional lymphoid organs and that antigen presentation occurs directly in the lung. More recent studies directly demonstrate that BALT can recruit and prime naive $\mathrm{T}$ cells. ${ }^{147}$ Importantly, $\mathrm{T}$-cell priming does not occur if BALT is not induced previously. ${ }^{147}$ Similar studies show that following BALT formation, adoptively transferred ovalbumin-specific $\mathrm{T}$ cells are recruited to BALT and proliferate locally in response to intratracheally administered ovalbumin-pulsed $\mathrm{DCs}^{38}$ and long-term B-cell responses to influenza are initiated in BALT. ${ }^{37}$ Memory T cells are also maintained in BALT without support from other secondary lymphoid organs and can be locally reactivated, ${ }^{142}$ demonstrating that BALT supports both primary and secondary immune responses.

\section{ECTOPIC FOLLICLES AND PATHOLOGY}

Immune responses in ectopic follicles are not always beneficial. For example, although the presence of BALT does not correlate with either respiratory allergy or asthma, ${ }^{150,151}$ the reactivity of BALT does increase in asthma patients. ${ }^{152}$ In addition, exposure to allergens, such as Aspergillus fumigatus, can lead to an asthma-like disease that is accompanied by the development of BALT with prominent IgE-expressing germinal centers. ${ }^{143}$ Similar results, including the formation of IgE-expressing germinal centers, are observed in mice following sensitization and pulmonary challenge with OVA. ${ }^{144}$

BALT development can also be induced by inflammatory stimuli like cigarette smoke. ${ }^{153}$ Moreover, smoking exacerbates BALT reactivity ${ }^{154}$ and promotes germinal center formation. ${ }^{152}$ Given the link between smoking and COPD, it is not surprising that BALT formation is most often observed in patients classified with GOLD (global initiative for chronic obstructive lung disease) stage 3 and stage 4 disease ${ }^{59}$ and strongly correlates with impaired lung function, ${ }^{59}$ suggesting the possibility that BALT has an important role in COPD pathogenesis. The germinal centers in the BALT of COPD patients have evidence of clonal B-cell proliferation and ongoing somatic hypermutation. ${ }^{112}$ In opposition to the idea that B cells and BALT contribute to the pathology of COPD, other studies show that exposure to cigarette smoke leads to the development of pulmonary emphysema to the same extent in normal and SCID mice, even though SCID mice completely lack B cells and BALT. ${ }^{155}$ Thus, although exposure to cigarette smoke promotes the formation of BALT in experimental model systems and BALT is associated with severe COPD in human patients, the causal link between BALT and COPD remains nebulous and it is unclear whether BALT is beneficial, harmful, or neutral to the progression of COPD. ${ }^{156}$

A subset of patients with rheumatoid arthritis (RA) and Sjogren's syndrome develop pulmonary symptoms, including the formation of BALT. ${ }^{62,63,157-159}$ BALT in RA and Sjogren's syndrome patients appears to contribute to local disease, as it often contains plasma cells producing IgG specific for citrullinated proteins and rheumatoid factor. ${ }^{63}$ Moreover, citrullinated proteins are observed in BALT areas of the lungs of RA patients, ${ }^{160}$ suggesting that autoantigens are located inside BALT areas. Interestingly, there is a strong association between RA and smoking, ${ }^{161}$ which may be explained by the ability of cigarette smoke to elicit the enzymes responsible for the citrullination process.

Although BALT is correlated with pathology in RA patients, it does not always exacerbate pathology in mouse models and even reduces pulmonary pathology in models of fibrosis, ${ }^{162}$ and infectious diseases, ${ }^{65,163}$ suggesting that the presence of BALT actually reduces pulmonary pathology. Thus, it is not clear whether the BALT found in patients with RA is exacerbating pulmonary pathology or may actually be preventing more severe disease. Moreover, BALT sporadically forms in the vicinity of lung tumors, ${ }^{63}$ including nonsmall-cell lung carcinoma. ${ }^{164}$ In these patients, the development of BALT is associated with a better long-term prognosis. ${ }^{164}$

\section{SUMMARY AND CONCLUDING REMARKS}

Immunity at mucosal surfaces is regulated by a variety of mucosal lymphoid tissues and organs that cooperate to generate immune responses to pathogens, contain commensal microbiota, and prevent unwanted inflammatory responses to food and other innocuous antigens. The functions of these lymphoid tissues are linked to both their development and their interactions with both microbiota and pathogens. As a result, our understanding of infectious diseases that target mucosal tissues or inflammatory diseases that occur as a result of dysregulated immunity in mucosal sites will require a further understanding of how these tissues sense and respond to the mucosal environment.

\section{ACKNOWLEDGMENTS}

This work was supported by an NWO-ALW top grant 854.10.005 (to R.E.M.) and by NIH grants HL069409, Al100127, and Al097357 (to T.D.R.). We thank Georg Kraal for redrawing the figure.

\section{DISCLOSURE}

The authors declared no conflict of interest.

(c) 2014 Society for Mucosal Immunology

\section{REFERENCES}

1. Bianconi, E. et al. An estimation of the number of cells in the human body. Ann. Hum. Biol. 40, 463-471 (2013).

2. Berg, R.D. The indigenous gastrointestinal microflora. Trends Microbiol. 4, 430-435 (1996).

3. Brestoff, J.R. \& Artis, D. Commensal bacteria at the interface of host metabolism and the immune system. Nat. Immunol. 14, 676-684 (2013).

4. Buffie, C.G. \& Pamer, E.G. Microbiota-mediated colonization resistance against intestinal pathogens. Nat. Rev. 13, 790-801 (2013). 
5. Maloy, K.J. \& Powrie, F. Intestinal homeostasis and its breakdown in inflammatory bowel disease. Nature 474, 298-306 (2011).

6. Pabst, O. \& Mowat, A.M. Oral tolerance to food protein. Mucosal Immunol. 5, 232-239 (2012)

7. Lambrecht, B.N. \& Hammad, H. Lung dendritic cells in respiratory viral infection and asthma: from protection to immunopathology. Annu. Rev. Immunol. 30, 243-270 (2012).

8. Randall, T.D., Carragher, D.M. \& Rangel-Moreno, J. Development of secondary lymphoid organs. Annu. Rev. Immunol. 26, 627-650 (2008).

9. Goodnow, C.C. Chance encounters and organized rendezvous. Immunol. Rev. 156, 5-10 (1997).

10. Chang, S.Y. et al. Colonic patches direct the cross-talk between systemic compartments and large intestine independently of innate immunity. J. Immunol. 180, 1609-1618 (2008).

11. Rosner, A.J. \& Keren, D.F. Demonstration of $M$ cells in the specialized follicle-associated epithelium overlying isolated lymphoid follicles in the gut. J. Leukocyte Biol. 35, 397-404 (1984).

12. Pabst, O. et al. Cryptopatches and isolated lymphoid follicles: dynamic lymphoid tissues dispensable for the generation of intraepithelial lymphocytes. Eur. J. Immunol. 35, 98-107 (2005).

13. Asanuma, $\mathrm{H}$. et al. Isolation and characterization of mouse nasalassociated lymphoid tissue. J. Immunol. Methods 202, 123-131 (1997).

14. Nagatake, T. et al. Id2-, RORgammat-, and LTbetaR-independent initiation of lymphoid organogenesis in ocular immunity. J. Exp. Med. 206, 2351-2364 (2009).

15. Mabbott, N.A., Donaldson, D.S., Ohno, H., Williams, I.R. \& Mahajan, A. Microfold (M) cells: important immunosurveillance posts in the intestinal epithelium. Mucosal Immunol. 6, 666-677 (2013).

16. Iwasaki, A. \& Kelsall, B.L. Localization of distinct Peyer's patch dendritic cell subsets and their recruitment by chemokines macrophage inflammatory protein (MIP)-3alpha, MIP-3beta, and secondary lymphoid organ chemokine. J. Exp. Med. 191, 1381-1394 (2000).

17. Moro, K. et al. Innate production of $\mathrm{T}(\mathrm{H}) 2$ cytokines by adipose tissueassociated c-Kit(+)Sca-1(+) lymphoid cells. Nature 463, 540-544 (2010).

18. Rangel-Moreno, J. et al. Omental milky spots develop in the absence of lymphoid tissue-inducer cells and support $\mathrm{B}$ and $\mathrm{T}$ cell responses to peritoneal antigens. Immunity 30, 731-743 (2009).

19. Beelen, R.H., Oosterling, S.J., van Egmond, M., van den Born, J. \& Zareie, M. Omental milky spots in peritoneal pathophysiology (spots before your eyes). Periton. Dial Int. 25, 30-32 (2005).

20. Carragher, D.M., Rangel-Moreno, J. \& Randall, T.D. Ectopic lymphoid tissues and local immunity. Semin Immunol 20, 26-42 (2008).

21. Honda, K. et al. Molecular basis for hematopoietic/mesenchymal interaction during initiation of Peyer's patch organogenesis. J. Exp. Med. 193, 621-630 (2001).

22. Cherrier, M., Sawa, S. \& Eberl, G. Notch, Id2, and RORgammat sequentially orchestrate the fetal development of lymphoid tissue inducer cells. J. Exp. Med. 209, 729-740 (2012).

23. Eberl, G. et al. An essential function for the nuclear receptor RORgam$\mathrm{ma}(\mathrm{t})$ in the generation of fetal lymphoid tissue inducer cells. Nat. Immunol. 5, 64-73 (2004).

24. Cupedo, T. \& Mebius, R.E. Role of chemokines in the development of secondary and tertiary lymphoid tissues. Semin. Immunol 15, 243-248 (2003).

25. van de Pavert, S.A. et al. Chemokine CXCL13 is essential for lymph node initiation and is induced by retinoic acid and neuronal stimulation. Nat. Immunol. 10, 1193-1199 (2009).

26. Mebius, R.E., Rennert, P. \& Weissman, I.L. Developing lymph nodes collect CD4 + CD3 - LTbeta + cells that can differentiate to APC, NK cells, and follicular cells but not Tor B cells. Immunity 7, 493-504 (1997).

27. Dejardin, E. et al. The lymphotoxin-beta receptor induces different patterns of gene expression via two NF-kappaB pathways. Immunity $\mathbf{1 7}$, 525-535 (2002).

28. Vondenhoff, M.F. et al. LTbetaR signaling induces cytokine expression and up-regulates lymphangiogenic factors in lymph node anlagen. J. Immunol. 182, 5439-5445 (2009).

29. Link, A. et al. Fibroblastic reticular cells in lymph nodes regulate the homeostasis of naive T cells. Nat. Immunol. 8, 1255-1265 (2007).
30. Nishikawa, S., Honda, K., Vieira, P. \& Yoshida, H. Organogenesis of peripheral lymphoid organs. Immunol. Rev. 195, 72-80 (2003).

31. Endres, R. et al. Mature follicular dendritic cell networks depend on expression of lymphotoxin beta receptor by radioresistant stromal cells and of lymphotoxin beta and tumor necrosis factor by B cells. J. Exp. Med. 189, 159-168 (1999).

32. Rennert, P.D., Browning, J.L., Mebius, R., Mackay, F. \& Hochman, P.S. Surface lymphotoxin alpha/beta complex is required for the development of peripheral lymphoid organs. J. Exp. Med. 184, 1999-2006 (1996).

33. Fukuyama, S. et al. Initiation of NALT organogenesis is independent of the IL-7R, LTbetaR, and NIK signaling pathways but requires the Id2 gene and $\mathrm{CD} 3(-) \mathrm{CD} 4(+) \mathrm{CD} 45(+)$ cells. Immunity 17, 31-40 (2002).

34. Baptista, A.P. et al. Colonic patch and colonic SILT development are independent and differentially regulated events. Mucosal Immunol. 6, 511-521 (2013).

35. Bouskra, D. et al. Lymphoid tissue genesis induced by commensals through NOD1 regulates intestinal homeostasis. Nature 456, 507-510 (2008).

36. Rangel-Moreno, J. et al. The development of inducible bronchusassociated lymphoid tissue depends on IL-17. Nat. Immunol. 12, 639-646 (2011).

37. GeurtsvanKessel, C.H. et al. Dendritic cells are crucial for maintenance of tertiary lymphoid structures in the lung of influenza virus-infected mice. J. Exp. Med. 206, 2339-2349 (2009).

38. Halle, S. et al. Induced bronchus-associated lymphoid tissue serves as a general priming site for Tcells and is maintained by dendritic cells. J. Exp. Med. 206, 2593-2601 (2009).

39. Ansel, K.M. et al. A chemokine-driven positive feedback loop organizes lymphoid follicles. Nature 406, 309-314 (2000).

40. Zhao, X. et al. CCL9 is secreted by the follicle-associated epithelium and recruits dome region Peyer's patch CD11b + dendritic cells. J. Immunol. 171, 2797-2803 (2003).

41. Rangel-Moreno, J. et al. Role of CXC chemokine ligand 13, CC chemokine ligand (CCL) 19, and CCL21 in the organization and function of nasal-associated lymphoid tissue. J. Immunol. 175, 4904-4913 (2005).

42. McDonald, K.G. et al. CC chemokine receptor 6 expression by B lymphocytes is essential for the development of isolated lymphoid follicles. Am. J. Pathol. 170, 1229-1240 (2007).

43. Ebisawa, M. et al. CCR6hiCD11c(int) B cells promote M-cell differentiation in Peyer's patch. Int. Immunol. 23, 261-269 (2011).

44. Lugering, A. et al. CCR6 identifies lymphoid tissue inducer cells within cryptopatches. Clin. Exp. Immunol. 160, 440-449 (2010).

45. Harmsen, A. et al. Cutting edge: organogenesis of nasal-associated lymphoid tissue (NALT) occurs independently of lymphotoxin-alpha (LT alpha) and retinoic acid receptor-related orphan receptor-gamma, but the organization of NALT is LT alpha dependent. J. Immunol. 168, 986-990 (2002).

46. Spits, H. \& Di Santo, J.P. The expanding family of innate lymphoid cells: regulators and effectors of immunity and tissue remodeling. Nat. Immunol. 12, 21-27 (2011).

47. Ansel, K.M., Harris, R.B. \& Cyster, J.G. CXCL13 is required for B1 cell homing, natural antibody production, and body cavity immunity. Immunity 16, 67-76 (2002).

48. Lochner, M. et al. Microbiota-induced tertiary lymphoid tissues aggravate inflammatory disease in the absence of RORgammat and LTi cells. J. Exp. Med. 208, 125-134 (2011)

49. Futterer, A., Mink, K., Luz, A., Kosco-Vilbois, M.H. \& Pfeffer, K. The lymphotoxin beta receptor controls organogenesis and affinity maturation in peripheral lymphoid tissues. Immunity 9, 59-70 (1998).

50. Rangel-Moreno, J., Moyron-Quiroz, J.E., Hartson, L., Kusser, K. \& Randall, T.D. Pulmonary expression of CXC chemokine ligand 13, CC chemokine ligand 19, and CC chemokine ligand 21 is essential for local immunity to influenza. Proc. Natl Acad. Sci. USA 104, 10577-10582 (2007).

51. Round, J.L. \& Mazmanian, S.K. The gut microbiota shapes intestinal immune responses during health and disease. Nat. Rev. Immunol. 9, 313-323 (2009) 
52. Krege, J., Seth, S., Hardtke, S., Davalos-Misslitz, A.C. \& Forster, R. Antigen-dependent rescue of nose-associated lymphoid tissue (NALT) development independent of LTbetaR and CXCR5 signaling. Eur. J. Immunol. 39, 2765-2778 (2009).

53. Jeong, K.I., Suzuki, H., Nakayama, H. \& Doi, K. Ultrastructural study on the follicle-associated epithelium of nasal-associated lymphoid tissue in specific pathogen-free (SPF) and conventional environment-adapted (SPF-CV) rats. J. Anat. 196 (Part 3), 443-451 (2000).

54. Terahara, K. et al. Comprehensive gene expression profiling of Peyer's patch M cells, villous M-like cells, and intestinal epithelial cells. J. Immunol. 180, 7840-7846 (2008).

55. Teitelbaum, R. et al. The $\mathrm{M}$ cell as a portal of entry to the lung for the bacterial pathogen Mycobacterium tuberculosis. Immunity 10, 641-650 (1999).

56. Wang, J., Gusti, V., Saraswati, A. \& Lo, D.D. Convergent and divergent development among $M$ cell lineages in mouse mucosal epithelium. J. Immunol. 187, 5277-5285 (2011).

57. Beelen, R.H., Fluitsma, D.M. \& Hoefsmit, E.C. The cellular composition of omentum milky spots and the ultrastructure of milky spot macrophages and reticulum cells. J. Reticuloendothel. Soc. 28, 585-599 (1980).

58. Ha, S.A. et al. Regulation of B1 cell migration by signals through Toll-like receptors. J. Exp. Med. 203, 2541-2550 (2006).

59. Hogg, J.C. et al. The nature of small-airway obstruction in chronic obstructive pulmonary disease. N. Engl. J. Med. 350, 2645-2653 (2004).

60. Demoor, T. et al. Role of lymphotoxin-alpha in cigarette smoke-induced inflammation and lymphoid neogenesis. Eur. Resp. J. 34, 405-416 (2009).

61. Suda, T. et al. Development of bronchus-associated lymphoid tissue in chronic hypersensitivity pneumonitis. Chest 115, 357-363 (1999).

62. Turesson, C. et al. Increased CD4 + T cell infiltrates in rheumatoid arthritis-associated interstitial pneumonitis compared with idiopathic interstitial pneumonitis. Arthritis Rheumat. 52, 73-79 (2005).

63. Rangel-Moreno, J. et al. Inducible bronchus-associated lymphoid tissue (iBALT) in patients with pulmonary complications of rheumatoid arthritis. J. Clin. Invest. 116, 3183-3194 (2006).

64. Perros, F. et al. Pulmonary lymphoid neogenesis in idiopathic pulmonary arterial hypertension. Am. J. Resp. Crit. Care Med. 185, 311-321 (2012).

65. Moyron-Quiroz, J.E. et al. Role of inducible bronchus associated lymphoid tissue (BALT) in respiratory immunity. Nat. Med. 10, 927-934 (2004).

66. Kahnert, A. et al. Mycobacterium tuberculosis triggers formation of lymphoid structure in murine lungs. J. Infect. Dis. 195, 46-54 (2007).

67. Khader, S.A. et al. In a murine tuberculosis model, the absence of homeostatic chemokines delays granuloma formation and protective immunity. J. Immunol. 183, 8004-8014 (2009).

68. Khader, S.A. et al. IL-23 is required for long-term control of Mycobacterium tuberculosis and B cell follicle formation in the infected lung. J. Immunol. 187, 5402-5407 (2011).

69. Slight, S.R. et al. CXCR5 + T helper cells mediate protective immunity against tuberculosis. J. Clin. Invest. 123, 712-726 (2013).

70. Gopal, R. et al. Interleukin-17-dependent CXCL13 mediates mucosal vaccine-induced immunity against tuberculosis. Mucos. Immunol. 6, 972-984 (2013).

71. Winter, S. et al. The chemokine receptor CXCR5 is pivotal for ectopic mucosa-associated lymphoid tissue neogenesis in chronic Helicobacter pylori-induced inflammation. J. Mol. Med. (Berl) 88, 1169-1180 (2010).

72. Mazzucchelli, L. et al. BCA-1 is highly expressed in Helicobacter pyloriinduced mucosa-associated lymphoid tissue and gastric lymphoma. J. Clin. Invest. 104, R49-R54 (1999).

73. Spahn, T.W. et al. Induction of colitis in mice deficient of Peyer's patches and mesenteric lymph nodes is associated with increased disease severity and formation of colonic lymphoid patches. Am. J. Pathol. 161, 2273-2282 (2002)

74. Nakashima, $Y$. et al. Enhanced expression of CXCL13 in human Helicobacter pylori-associated gastritis. Dig. Dis. Sci. 56, 2887-2894 (2011).

75. Zhuang, Y. et al. Helicobacter pylori-infected macrophages induce Th17 cell differentiation. Immunobiology 216, 200-207 (2011).

76. Fleige, $\mathrm{H}$. et al. Induction of BALT in the absence of IL-17. Nat. Immunol. 13, 1. author reply 2 (2012)
77. Botelho, F.M. et al. IL-1alpha/L-1R1 expression in chronic obstructive pulmonary disease and mechanistic relevance to smoke-induced neutrophilia in mice. PLoS One 6, e28457 (2011).

78. Pauwels, N.S. et al. Role of IL-1alpha and the NIrp3/caspase-1/IL-1beta axis in cigarette smoke-induced pulmonary inflammation and COPD. Eur. Resp. J. 38, 1019-1028 (2011).

79. Randolph, G.J., Ochando, J. \& Partida-Sanchez, S. Migration of dendritic cell subsets and their precursors. Annu. Rev. Immunol. 26, 293-316 (2008).

80. Varol, C. et al. Intestinal lamina propria dendritic cell subsets have different origin and functions. Immunity 31, 502-512 (2009).

81. Ballesteros-Tato, A., Leon, B., Lund, F.E. \& Randall, T.D. Temporal changes in dendritic cell subsets, cross-priming and costimulation via CD70 control CD8(+) T cell responses to influenza. Nat. Immunol. 11, 216-224 (2010)

82. GeurtsvanKessel, C.H. et al. Clearance of influenza virus from the lung depends on migratory langerin $+\mathrm{CD} 11 \mathrm{~b}-$ but not plasmacytoid dendritic cells. J. Exp. Med. 205, 1621-1634 (2008).

83. GeurtsvanKessel, C.H. \& Lambrecht, B.N. Division of labor between dendritic cell subsets of the lung. Mucosal Immunol. 1, 442-450 (2008).

84. Pabst, O. \& Bernhardt, G. The puzzle of intestinal lamina propria dendritic cells and macrophages. Eur. J. Immunol. 40, 2107-2111 (2010).

85. McDole, J.R. et al. Goblet cells deliver luminal antigen to CD103+ dendritic cells in the small intestine. Nature 483, 345-349 (2012).

86. del Rio, M.L., Bernhardt, G., Rodriguez-Barbosa, J.I. \& Forster, R. Development and functional specialization of CD103 + dendritic cells. Immunol. Rev. 234, 268-281 (2010).

87. Hintzen, G. et al. Induction of tolerance to innocuous inhaled antigen relies on a CCR7-dependent dendritic cell-mediated antigen transport to the bronchial lymph node. J Immunol 177, 7346-7354 (2006).

88. Eri, R.D. et al. An intestinal epithelial defect conferring ER stress results in inflammation involving both innate and adaptive immunity. Mucos. Immunol. 4, 354-364 (2011).

89. Van der Sluis, M. et al. Muc2-deficient mice spontaneously develop colitis, indicating that MUC2 is critical for colonic protection. Gastroenterology 131, 117-129 (2006).

90. Hapfelmeier, S. et al. Microbe sampling by mucosal dendritic cells is a discrete, MyD88-independent step in DeltainvG S. Typhimurium colitis. J. Exp. Med. 205, 437-450 (2008).

91. Niess, J.H. et al. CX3CR1-mediated dendritic cell access to the intestinal lumen and bacterial clearance. Science 307, 254-258 (2005).

92. Schulz, O. et al. Intestinal CD103+, but not CX3CR1+, antigen sampling cells migrate in lymph and serve classical dendritic cell functions. J. Exp. Med. 206, 3101-3114 (2009).

93. Schulz, O. \& Pabst, O. Antigen sampling in the small intestine. Trends Immunol. 34, 155-161 (2013).

94. Diehl, G.E. et al. Microbiota restricts trafficking of bacteria to mesenteric lymph nodes by CX(3)CR1(hi) cells. Nature 494, 116-120 (2013).

95. Kraehenbuhl, J.P. \& Neutra, M.R. Epithelial M cells: differentiation and function. Annu. Rev. Cell Dev. Biol. 16, 301-332 (2000).

96. Hsieh, E.H. et al. CD137 is required for M cell functional maturation but not lineage commitment. Am. J. Pathol. 177, 666-676 (2010).

97. Jang, M.H. et al. Intestinal villous M cells: an antigen entry site in the mucosal epithelium. Proc. Natl. Acad. Sci. USA 101, 6110-6115 (2004).

98. Kim, D.Y. et al. The airway antigen sampling system: respiratory $M$ cells as an alternative gateway for inhaled antigens. J. Immunol. 186, 4253-4262 (2011).

99. Sato, S. et al. Transcription factor Spi-B-dependent and -independent pathways for the development of Peyer's patch M cells. Mucos. Immunol. 6, 838-846 (2013).

100. Verbrugghe, P. et al. Murine $M$ cells express annexin $V$ specifically. J. Pathol. 209, 240-249 (2006).

101. Velin, D., Fotopoulos, G., Luthi, F. \& Kraehenbuhl, J.P. The nasal-associated lymphoid tissue of adult mice acts as an entry site for the mouse mammary tumor retrovirus. J. Exp. Med. 185, 1871-1876 (1997).

102. Park, H.S., Francis, K.P., Yu, J. \& Cleary, P.P. Membranous cells in nasal-associated lymphoid tissue: a portal of entry for the respiratory mucosal pathogen group A streptococcus. J. Immunol. 171, 2532-2537 (2003). 
103. Owen, S.J. et al. Nasal-associated lymphoid tissue and olfactory epithelium as portals of entry for Burkholderia pseudomallei in murine melioidosis. J. Infect. Dis. 199, 1761-1770 (2009).

104. Lelouard, H., Fallet, M., de Bovis, B., Meresse, S. \& Gorvel, J.P. Peyer's patch dendritic cells sample antigens by extending dendrites through $M$ cell-specific transcellular pores. Gastroenterology 142, 592-601 e593 (2012).

105. Tango, M., Suzuki, E., Gejyo, F. \& Ushiki, T. The presence of specialized epithelial cells on the bronchus-associated lymphoid tissue (BALT) in the mouse. Arch. Histol. Cytol. 63, 81-89 (2000).

106. Sminia, T., van der Brugge-Gamelkoorn, G.J. \& Jeurissen, S.H. Structure and function of bronchus-associated lymphoid tissue (BALT). Crit. Rev. Immunol. 9, 119-150 (1989).

107. Gregson, R.L., Edmondson, N.A. \& Plesch, B. Preferential uptake of soluble antigen by respiratory tract epithelium overlying bronchusassociated lymphoid tissue in the rat. Adv. Exp. Med. Biol. 149, 499-505 (1982).

108. van der Brugge-Gamelkoorn, G.J., van de Ende, M. \& Sminia, T. Changes occurring in the epithelium covering the bronchus-associated lymphoid tissue of rats after intratracheal challenge with horseradish peroxidase. Cell Tissue Res. 245, 439-444 (1986).

109. Woodland, D.L. \& Randall, T.D. Anatomical features of anti-viral immunity in the respiratory tract. Semin. Immunol. 16, 163-170 (2004).

110. Hiramatsu, K. et al. Inhalation of diesel exhaust for three months affects major cytokine expression and induces bronchus-associated lymphoid tissue formation in murine lungs. Exp. Lung Res. 29, 607-622 (2003).

111. Lee, K.P. \& Kelly, D.P. Translocation of particle-laden alveolar macrophages and intra-alveolar granuloma formation in rats exposed to Ludox colloidal amorphous silica by inhalation. Toxicology 77, 205-222 (1993).

112. van der Strate, B.W. et al. Cigarette smoke-induced emphysema: a role for the B cell? Am. J. Resp. Crit. Care Med. 173, 751-758 (2006)

113. Sorensen, E.W. et al. Omental immune aggregates and tumor metastasis within the peritoneal cavity. Immunol. Res. 45, 185-194 (2009).

114. Craig, S.W. \& Cebra, J.J. Peyer's patches: an enriched source of precursors for IgA-producing immunocytes in the rabbit. J. Exp. Med. 134, 188-200 (1971).

115. Muramatsu, M. et al. Class switch recombination and hypermutation require activation-induced cytidine deaminase (AID), a potential RNA editing enzyme. Cell 102, 553-563 (2000).

116. Bergqvist, P., Stensson, A., Lycke, N.Y. \& Bemark, M. Tcell-independent IgA class switch recombination is restricted to the GALT and occurs prior to manifest germinal center formation. J. Immunol. 184, 3545-3553 (2010).

117. Shikina, T. et al. IgA class switch occurs in the organized nasopharynxand gut-associated lymphoid tissue, but not in the diffuse lamina propria of airways and gut. J. Immunol. 172, 6259-6264 (2004).

118. Fagarasan, S., Kinoshita, K., Muramatsu, M., Ikuta, K. \& Honjo, T. In situ class switching and differentiation to IgA-producing cells in the gut lamina propria. Nature 413, 639-643 (2001).

119. Kinoshita, K., Harigai, M., Fagarasan, S., Muramatsu, M. \& Honjo, T. A hallmark of active class switch recombination: transcripts directed by promoters on looped-out circular DNAs. Proc. Natl Acad. Sci. USA 98, 12620-12623 (2001).

120. Tsuji, M. et al. Requirement for lymphoid tissue-inducer cells in isolated follicle formation and T cell-independent immunoglobulin A generation in the gut. Immunity 29, 261-271 (2008).

121. Lorenz, R.G. \& Newberry, R.D. Isolated lymphoid follicles can function as sites for induction of mucosal immune responses. Ann. NY Acad. Sci. 1029, 44-57 (2004).

122. Kang, H.S. et al. Signaling via LTbetaR on the lamina propria stromal cells of the gut is required for IgA production. Nat. Immunol. 3, 576-582 (2002).

123. Berberich, S., Forster, R. \& Pabst, O. The peritoneal micromilieu commits B cells to home to body cavities and the small intestine. Blood 109, 4627-4634 (2007)

124. Thurnheer, M.C., Zuercher, A.W., Cebra, J.J. \& Bos, N.A. B1 cells contribute to serum IgM, but not to intestinal IgA, production in gnotobiotic lg allotype chimeric mice. J. Immunol. 170, 4564-4571 (2003).

125. Wu, H.Y., Nguyen, H.H. \& Russell, M.W. Nasal lymphoid tissue (NALT) as a mucosal immune inductive site. Scand. J. Immunol. 46, 506-513 (1997).
126. Wu, H.Y., Nikolova, E.B., Beagley, K.W. \& Russell, M.W. Induction of antibody-secreting cells and T-helper and memory cells in murine nasal lymphoid tissue. Immunology 88, 493-500 (1996).

127. Matsuo, K. et al. Cytokine mRNAs in the nasal-associated lymphoid tissue during influenza virus infection and nasal vaccination. Vaccine $\mathbf{1 8 ,}$ 1344-1350 (2000).

128. Asanuma, H., Aizawa, C., Kurata, T. \& Tamura, S. IgA antibody-forming cell responses in the nasal-associated lymphoid tissue of mice vaccinated by intranasal, intravenous and/or subcutaneous administration. Vaccine 16, 1257-1262 (1998).

129. Liang, B., Hyland, L. \& Hou, S. Nasal-associated lymphoid tissue is a site of long-term virus-specific antibody production following respiratory virus infection of mice. J. Virol. 75, 5416-5420 (2001).

130. Heritage, P.L., Brook, M.A., Underdown, B.J. \& McDermott, M.R. Intranasal immunization with polymer-grafted microparticles activates the nasal-associated lymphoid tissue and draining lymph nodes. Immunology 93, 249-256 (1998).

131. Tamura, S., Funato, H., Nagamine, T., Aizawa, C. \& Kurata, T. Effectiveness of cholera toxin B subunit as an adjuvant for nasal influenza vaccination despite pre-existing immunity to CTB. Vaccine 7, 503-505 (1989).

132. Tamura, S. et al. Antibody-forming cells in the nasal-associated lymphoid tissue during primary influenza virus infection. J. Gen. Virol. 79 (Part 2), 291-299 (1998)

133. Zuercher, A.W., Coffin, S.E., Thurnheer, M.C., Fundova, P. \& Cebra, J.J. Nasal-associated lymphoid tissue is a mucosal inductive site for virus-specific humoral and cellular immune responses. J. Immunol. 168, 1796-1803 (2002)

134. Boyden, A.W., Legge, K.L. \& Waldschmidt, T.J. Pulmonary infection with influenza A virus induces site-specific germinal center and T follicular helper cell responses. PLoS One 7, e40733 (2012).

135. Petukhova, G. et al. Comparative studies of local antibody and cellular immune responses to influenza infection and vaccination with live attenuated reassortant influenza vaccine (LAIV) utilizing a mouse nasal-associated lymphoid tissue (NALT) separation method. Vaccine 27, 2580-2587 (2009).

136. Sealy, R., Webby, R.J., Crumpton, J.C. \& Hurwitz, J.L. Differential localization and function of antibody-forming cells responsive to inactivated or live-attenuated influenza virus vaccines. Int. Immunol. 25, 183-195 (2013).

137. Shimoda, M. et al. Isotype-specific selection of high affinity memory B cells in nasal-associated lymphoid tissue. J. Exp. Med. 194, 1597-1607 (2001).

138. Wiley, J.A., Tighe, M.P. \& Harmsen, A.G. Upper respiratory tract resistance to influenza infection is not prevented by the absence of either nasal-associated lymphoid tissue or cervical lymph nodes. $J$. Immunol. 175, 3186-3196 (2005).

139. Sabirov, A. \& Metzger, D.W. Intranasal vaccination of infant mice induces protective immunity in the absence of nasal-associated lymphoid tissue. Vaccine 26, 1566-1576 (2008).

140. Plesch, B.E., Gamelkoorn, G.J. \& van de Ende, M. Development of bronchus associated lymphoid tissue (BALT) in the rat, with special reference to T- and B-cells. Dev. Comp. Immunol. 7, 179-188 (1983).

141. Kolopp-Sarda, M.N., Bene, M.C., Massin, N., Moulin, J.J. \& Faure, G.C. Immunohistological analysis of macrophages, B-cells, and T-cells in the mouse lung. Anatom. Rec. 239, 150-157 (1994).

142. Moyron-Quiroz, J.E. et al. Persistence and responsiveness of immunologic memory in the absence of secondary lymphoid organs. Immunity 25 , 643-654 (2006)

143. Slavin, R.G. et al. Localization of IgE to lung germinal lymphoid follicles in a patient with allergic bronchopulmonary aspergillosis. J. Allergy Clin. Immunol. 90, 1006-1008 (1992).

144. Chvatchko, Y., Kosco-Vilbois, M.H., Herren, S., Lefort, J. \& Bonnefoy, J.Y. Germinal center formation and local immunoglobulin E (IgE) production in the lung after an airway antigenic challenge. J. Exp. Med. 184, 2353-2360 (1996).

145. Gajewska, B.U. et al. Generation of experimental allergic airways inflammation in the absence of draining lymph nodes. J. Clin. Invest. 108, 577-583 (2001) 
146. Moyron-Quiroz, J., Rangel-Moreno, J., Carragher, D.M. \& Randall, T.D. The function of local lymphoid tissues in pulmonary immune responses. Adv. Exp. Med. Biol. 590, 55-68 (2007).

147. Day, T.A. et al. Secondary lymphoid organs are dispensable for the development of T-cell-mediated immunity during tuberculosis. Eur. J. Immunol. 40, 1663-1673 (2010).

148. Kashino, S.S. et al. Initiation of acquired immunity in the lungs of mice lacking lymph nodes after infection with aerosolized Mycobacterium tuberculosis. Am. J. Pathol. 176, 198-204 (2010).

149. Constant, S.L. et al. Resident lung antigen-presenting cells have the capacity to promote Th2 T cell differentiation in situ. J. Clin. Invest. 110, 1441-1448 (2002).

150. Sue-Chu, M. et al. Lymphoid aggregates in endobronchial biopsies from young elite cross-country skiers. Am. J. Resp. Crit. Care Med. 158, 597-601 (1998).

151. Heier, I. et al. Bronchial response pattern of antigen presenting cells and regulatory T cells in children less than 2 years of age. Thorax $63,703-709$ (2008).

152. Elliot, J.G. et al. Aggregations of lymphoid cells in the airways of nonsmokers, smokers, and subjects with asthma. Am. J. Resp. Crit. Care Med. 169, 712-718 (2004).

153. Bosken, C.H., Hards, J., Gatter, K. \& Hogg, J.C. Characterization of the inflammatory reaction in the peripheral airways of cigarette smokers using immunocytochemistry. Am. Rev. Resp. Dis. 145, 911-917 (1992).

154. Escolar Castellon, J.D., Escolar Castellon, A., Roche Roche, P.A. \& Minana Amada, C. Bronchial-associated lymphoid tissue (BALT) response to airway challenge with cigarette smoke, bovine antigen and anti-pulmonary serum. Histol. Histopathol. 7, 321-328 (1992).
155. D'Hulst, A.I. et al. Cigarette smoke-induced pulmonary emphysema in scidmice. Is the acquired immune system required? Resp. Res. 6, 147 (2005).

156. Brusselle, G.G., Demoor, T., Bracke, K.R., Brandsma, C.A. \& Timens, W. Lymphoid follicles in (very) severe COPD: beneficial or harmful? Eur. Resp. J. 34, 219-230 (2009).

157. Atkins, S.R. et al. Morphologic and quantitative assessment of CD20 + B cell infiltrates in rheumatoid arthritis-associated nonspecific interstitial pneumonia and usual interstitial pneumonia. Arthritis Rheumat. 54, 635-641 (2006).

158. Hayakawa, H. et al. Diffuse panbronchiolitis and rheumatoid arthritisassociated bronchiolar disease: similarities and differences. Intern. Med. 37, 504-508 (1998).

159. Sato, A., Hayakawa, H., Uchiyama, H. \& Chida, K. Cellular distribution of bronchus-associated lymphoid tissue in rheumatoid arthritis. Am. J. Resp. Crit. Care Med. 154, 1903-1907 (1996).

160. Bongartz, T. et al. Citrullination in extra-articular manifestations of rheumatoid arthritis. Rheumatology (Oxford) 46, 70-75 (2007).

161. Klareskog, L. et al. A new model for an etiology of rheumatoid arthritis: smoking may trigger HLA-DR (shared epitope)-restricted immune reactions to autoantigens modified by citrullination. Arthritis Rheumat. 54, 38-46 (2006).

162. Shilling, R.A. et al. Autoreactive Tand B cells induce development of BALTlike tissue in the lung. Am. J. Resp. Cell Mol. Biol. 48, 406-414 (2013).

163. Wiley, J.A. et al. Inducible bronchus-associated lymphoid tissue elicited by a protein cage nanoparticle enhances protection in mice against diverse respiratory viruses. PLoS One 4, e7142 (2009).

164. Dieu-Nosjean, M.C. et al. Long-term survival for patients with non-smallcell lung cancer with intratumoral lymphoid structures. J. Clin. Oncol. 26, 4410-4417 (2008). 